\title{
INEQUALITIES INVOLVING THE NORM OF SOME LINEAR OPERATORS WITH APPLICATION TO APPROXIMATION PROCEDURES
}

\author{
A. I. MitREA
}

Abstract. Inequalities regarding the norm of some generalized projection operators are established, in order to describe the topological structure of the set of unbounded divergence for corresponding approximation procedures.

Mathematics subject classification (2000): 41A05.

Key words and phrases: projection operators, superdense set.

\section{REFERENCES}

[1] S. CobZaŞ And I. MunTEan, Condensation of Singularities and Divergence Results in Approximation Theory, J. Approx. Theory, 31 (1981), 138-153.

[2] G. HaLÁsz, On projection into the space of trigonometric polynomials, Acta Sci. Math. (Szeged), 57 (1993), 353-366.

[3] S. M. LOZINSKI, On a class of linear operators (Russian), Dokl. Akad. Nauk, SSSR 61 (1948), 193-196.

[4] A. I. MitREA, Convergence and Superdense Unbounded Divergence in Approximation Theory, Transilvania Press, Cluj, Romania, 1998.

[5] S. A. Teliakovski, On the norm of some polynomials linear operators (Russian), Mat. Sb. 68 (110), No. 4 (1965), 561-569. 